\title{
From Emotion to Mobilization: Examples of the Confrontation of Human Tragedies in the Social Networks with Images: The Cases of Monique Koumatekel and Blériot Tsanou
}

\author{
Ndibi Ola'a Frederic \\ Advanced School of Mass Cmmunication (ASMAC), Univerity of Yaounde II, Yaounde, Cameroon \\ Email: ndibif@yahoo.com
}

How to cite this paper: Frederic, N.O. (2020) From Emotion to Mobilization: Examples of the Confrontation of Human Tragedies in the Social Networks with Images: The Cases of Monique Koumatekel and Blériot Tsanou. Int. J. Communications, Network and System Sciences, 13, 29-43.

https://doi.org/10.4236/ijcns.2020.133003

Received: March 16, 2020

Accepted: March 28, 2020

Published: March 31, 2020

Copyright ( 2020 by author(s) and Scientific Research Publishing Inc. This work is licensed under the Creative Commons Attribution International License (CC BY 4.0).

http://creativecommons.org/licenses/by/4.0/

\begin{abstract}
To produce emotion, the discourse of social networks tries to confront the reader with social reality. The mediation activity at the heart of any communication activity is hidden. This process is also based on the use of figures to express the unspeakable by the shock of images, which allows the reader to experience emotion but also to push him to act. It is the link between the emotion of an individual targeted by social networks and collective mobilization, which we wish to consider as a means of relaunching the debate and drawing attention to social issues, thus allowing us to rethink sociability with politics.
\end{abstract}

\section{Keywords}

Social Media, Images of Tragedies, Emotion, Mobilization, Sociability, Internet

\section{Introduction}

"Disaster", "drama", "tragedy" are synonyms often used to characterize all events that belong to the phenomenal register and that have an emotional intensity. They are what appears, and what arises in an unpredictable way. Emotion has become very present in the media today, especially in the audio-visual media. On television as in the social networks of the Internet, films, so-called reality shows do not have a monopoly on the exposure of suffering. Indeed, it happens that the pain experienced by individuals is exposed to television news or in live broadcasts. In general, media speeches make extensive use of emotion and con- 
verge in the register of compassion, dramatization, feeling, anger. The Cameroonian media are not to be outdone. Cameroonians still have in their minds images of the abuses, crimes of the Boko Haram sect or secessionists in the North-West and South-West regions who circulated in social networks, or the railway accident that occurred on 21 October 2016 in Eséka, whose images were widely shared immediately after its occurrence.

Indeed, recently, Cameroonians have been moved and overwhelmed by amateur videos captured by smartphones. First, the Monique Koumatekel case begins with the discovery in social networks, on the morning of Saturday, March 12,2016 , of a scene taking place in front of the closed door of the emergency room of the Laquintinie Hospital in Douala. A woman has just been turned away from the hospital, a doctor having reported her death; this woman, pregnant with twins, is about to give birth; her sister thought she could save the children by opening her belly inside the hospital with a blade, and on the ground. In addition, there is a case of the young high school student Blériot Tsanou stabbed to death by one of his classmates on 29 March 2019 during the handing over of the Second Term report cards. A video is broadcast on social networks showing the nurses who, during the resuscitation session of young Blériot, enjoyed filming the scene. Cameroon is in shock and the event provokes strong emotion. For our study, we selected these two events because of the sufficient importance of the facts to have left their mark on people's minds. These two cases, extensively commented on by Cameroonian newspapers, provoke demonstrations in Douala, the most important of which was the march in Douala on 14 March 2016. Several demonstrators march with banners on which they have written: "No more Koumatekel Monique in my country!!!". On this occasion, the emotion conveyed by the videos and media seems to have been part of the mobilization process.

We would like to make a methodological remark here: in this study, we will not analyse the media coverage of the dramas of Monique Koumatekel and Blériot Tsanou as Noah (2016) [1] or other European authors who worked on the attacks of 11 September 2001, or the events that occurred in the stands of the Heysel stadium in 1985 in Belgium. Indeed, traditional media are being doubled by social networks; we are witnessing an increasing proliferation of images captured in public and private places, and instantly broadcast. There is no longer reality on one side and its representation or media treatment on the other. Everything is now and immediately image. We will rely on forms of media situations that capture the subject on the spot and are broadcast on social networks by the public. This is the case for the videos described above, which are amateur videos broadcast on social networks. These moments are therefore particular in relation to the usual media production, insofar as the media itself, or more precisely the media institution, the Internet, in this case has no power of production, nor even a responsibility in the diffusion. In addition, we refuse to allow the producers and broadcasters of these films any major narrative or dramatic construction; they are amateurs who capture on the spot an action during which 
they have no processing power. What seems significant to us is to analyze the "discursive process" by which emotion can be set up, i.e. treat it as a "targeted effect, but without ever having a guarantee on the effect produced", notes Charaudeau (2000, pp. 125-155) [2]. These videos are objects with high emotional potential. These dramas could have remained miscellaneous facts like thousands of others, but one element explains why they were important: the image of the caesarean section and resuscitation, which have been widely circulated on social networks. The image therefore appears as a powerful vector of emotion. What is this "media" emotion? Our main hypothesis is that, in order to produce emotion, the "media" discourse of the designers-broadcasters attempts to confront the reader directly with the raw social reality. In doing so, it masks the symbolic dimension that is at the heart of media activity. The work on the production of public emotion, and its passage to a collective act pushing to act, was then based on several grounds:

- Iconic, sound and plastic analyses of the videos, objects of our reflexion;

- The analysis of a certain number of media reports on the mobilisations.

In an attempt to understand what this "media" emotion consists of, this reflection identifies, in an analytical approach, a media device that is based on the perception of a dramatic situation in its raw state and leads to public emotion. From the moment this situation is inscribed in the emotional framework, we want to describe the visual staging of this emotion. Finally, we observe that this discourse is not limited to the invitation to share suffering: it aims at an ethical and political positioning.

Several conclusions were drawn:

- In terms of content, videos draw their value from the exceptional nature of the encounter between an event and amateur video. The drama, the new and the unpredictable create the shock of the images;

- In terms of form, social networks have an impact on our emotions, i.e. they promote them and, often, it is the immediacy that prevails;

- On the relational level, the video discourse is intended to produce the link, the collective, based on individual emotions.

In short, we are witnessing new sociabilities and the constitution of new political and public spaces.

\section{The Media System}

The images of the dramas of Monique Koumatekel and Blériot Tsanou that have been broadcast on social networks are often presented today as having given rise to a media universe where nothing will be the same as before, a place where suffering is at the heart of the media system. We want to examine in detail the vision mechanisms implemented in these two short videos to analyze the visibility system to which they belong. The aim is to analyse the discovery of the dramas based on the images broadcast on social networks.

In general, the media space very often refers to the outdoor event space, the 
field of facts and the reception area. In this case, the field is used as the territory of the event and as a substitute for the installation of a stage space or studio in the auditorium; the foyer is of course the place most often used for the reception.

\subsection{The Stage System}

The scenic setting is exactly the same for both events; these are the hospitals that serve as the narrative framework for these stories; for the first, the scene takes place at Laquintinie Hospital and, the second at Deido District Hospital, both spatially located in Douala. The filmed scene and the staging, for the first event, take place on the floor in front of the closed door of an operating theatre in the compound of Laquintinie Hospital; while for the second, they take place in the emergency room of Deido District Hospital during the resuscitation of the young Blériot. Symbolically naming the places where the two events took place creates misunderstanding, because in these places, one is supposed to save lives. Generally speaking, what we know about hospitals is that they are closed environments. Very often, the television images we receive from our traditional media are stereotypical: most of them concern images relating to a body lift, accident victims or interviews with patients on their hospital beds. While our traditional media have always shown a certain modesty in their treatment, and a kind of respect for the victims of tragedies, social networks tend to expose situations captured on the spot as they are. These videographic productions are the symptom that there is no longer any moment, including in the private sphere, which escapes visual capture, a smartphone is always already there to record or broadcast live. We are all potentially captured and sensors at the same time. Some places, such as the Presidency of the Republic of Cameroon, have banned the presence of smartphones during certain public events such as the National Day of May 20. We are now in the social report of the show analyzed by Debord, "the show is the present model of socially dominant life" (1967, p. 11) [3]. That is to say, there is no longer reality on one side and its representation on the other, everything is immediately image.

It should be recalled that in France, the early 1990s on television saw the emergence of a telescoping between private and public life, which was widely highlighted by sociologists. According to Ehrenberg and Chambat, the gradual erasure of politics and social ties was the fact that individuals were now seeking to address their problems in the public sphere through what they called "a process (...) of publicizing the private sector" (1993, p. 10) [4]. Dominique Volton (1992) [5], saw it as an overlap between public space, political space and civil society and a capture by the media scene of certain issues that, again, at other times, would have remained in the private domain. It is another form of "private advertising" that we have endeavoured to describe here: the one that appears in social networks in unusual places, and that feeds on the profusion of images made daily and on all occasions by amateur videographers with smartphones. Indeed, the private and public spheres are unexpectedly intertwined. 
In any case, it can be noted that hospitals previously intended for other functions are now occasionally invested in its closed sites and closed to any camera.

\subsection{The Iconic Discourse}

We are faced with extraordinarily intense brief events that brutally erupt into the daily lives of Cameroonians, moving them, and upsetting them.

The confrontation with the images of the two videos is a clear example of the life-death confrontation that plunges the reader into his own confrontation with life and death. These two videos set up an iconic mechanism whose emotional aim is quite perceptible. In both cases, the authors focus on describing a reality considered unacceptable, the videos show the desecration of the bodies. Death became public, from the moment it occurred in front of the image sensors and in the context of a planetary event. The first video describes the opening of Monique Koumatekel's belly to extract babies in the open air. Indeed, on Saturday, March 12, 2016, Monique Koumatekel, a 31-year-old mother of three children, arrived at the Laquintinie hospital pregnant with twins. Monique was not treated by the medical profession. When she died, her children in her belly were still moving, according to the words of her relatives, who were desperate for help; but no one took care of her, she lay there, in the indifference of the medical profession, amid the cries and tears of people who were completely helpless in the face of the situation. It was in dismay, still in the absence of medical personnel, that the deceased's niece took the initiative to open her belly in a deliberate gesture in an attempt to save the babies. The video sets up a visual mechanism whose emotional aim is present, the video describes a reality that touches on the incredible, of which we cannot find in our imagination antecedents or find facts that are partly similar: in the hospital, surgery is performed with a blade by an unqualified person for nearly ten minutes. We are witnessing almost a madness in its pure state, without qualifiers, that no despair can justify. The violence of the elements is too strong for the facts to speak for themselves, and thus give a large place to the elements likely to provoke the readers' emotions: the act of surgery by the blade, the extraction of the two deceased babies, the abundant presence of fresh blood, testify to an accumulation of situations whose sight is painful for us but which we are watching. We see people around the scene and we hear screams, cries and even explanations from the calm but angry crowd of family members, hospital patients and onlookers (for example, we learn from their comments that they are boys when they are being extracted). Faced with this sequence plan of opening the belly and extracting the two babies, the Director adopted a strategy that cancelled all mediation. Nel distinguishes "two varieties of iconic regimes that structure audiovisual programmes: presentation, in situations of live or deferred non-reporting and representation, which introduces restructuring and contributes to the construction of worlds" $(1998$, p. 68) [6]. In this case study, the scene captured by the smartphone is necessarily in presentation. It is no longer a question of astonishment at the images that are 
difficult to understand, but of the demonstration of the caesarean section. This is the demonstration of the scene of opening the belly with a blade and the extraction of babies which here takes the form of a denunciation. Nevertheless, in the face of the erasure of mediation, the enunciator displays intentionality and therefore a certain number of biases, as well as rules of plastic vocabulary, grammar and rhetoric of the image. The staging is quite effective, the enunciator shows us the subject not from the front but from the side, he takes an oblique point of view. Indeed, this position corresponds to a descriptive point of view. In the image, we have a main scene that serves as a symbolic scene and concentrates the reader's attention. We also notice the plurality of audiences: in the context of the image, we see some who film the scene with their smartphone, others who provide an explanatory framework to the images, the images are, from that moment on, accompanied by comments, screams and tears. The staging and processing of the scene uses live technology, even if the simultaneity of the recording and broadcasting of images is not acquired: the film is a sequence shot, it is filmed continuously, it does not admit any clear cut-off, nor any change of axis and point of view. Undoubtedly that such a mechanism carries a strong promise of authenticity, we are in touch here with reality. The representation or report would never reproduce the same degree of realism. The visual mechanism used in this case, therefore, makes the reality of the event present all the more strongly as it is the imagination of the reader who works; the reader is placed in ignorance of the fate of the two babies, are they dead or alive?

On the other hand, in the case of Blériot Tsanou, the visual mechanism used in the video presented by the nurses seems, from the outset, to be much less emotional than the first video. This iconic operation spectacularly excludes the death of the young Blériot: the first index of moderation of this mechanism is that the event does not show the identification elements of the young Blériot. He is treated with a certain distance in order to favour suggestion, the nurses are in the foreground of the scene, relegating the body of the young Blériot to the background, and proposing a very disturbing reading. Indeed, the video broadcast on social networks shows the nurses who, during the resuscitation session of young Blériot stabbed to death by his classmate, took pleasure in filming the scene and broadcasting it immediately. A behaviour evoked a strong emotion among Internet users who shouted their anger. How can we understand that images of an operating room, an emergency room, a family pain, a tragedy in a hospital are put on social networks by the staff of the Deido District Hospital?

The staging of this video places the reader in front of the nurses, and his position in the mechanism is that of a spectator who sees the story being played before his eyes, while being able to see only this theatrical staging of the nurses in front of death: the nurses deliberately refused to give their assistance and their experience to this young man who died in front of the camera on their phone. It is the carelessness in the face of the death and suffering of the bereaved family. For Internet users, it is still intolerable that we lose respect for the dead. There is 
a clear desire on the part of nurses to seek the sensational in the visual treatment of what is in itself a moving event. In this case, we can wonder about the motivations of these three nurses. What do they want to do with this apparent "life-death" contradiction. This topical work, which celebrates the death of the young Blériot, has rather provoked a wave of indignation and anger. This case, which is more recent than the first, cannot be understood without a link with the first, as both share the fact that they take place within the confines of a hospital in the city of Douala. In addition, the medical profession is pinned down in both cases; however, we know that the medical profession must take care of patients in accordance with professional ethics.

These events, and the topics covered, partly deviate from the usual rules of media staging. If the world captured by television, for example, is necessarily in representation, the world captured by social networks is in presentation: these images acquire an exceptional status in the field of television images.

\subsection{The Technical System}

The communication situation that concerns us here is composed of an outdoor event space or territory and the reception areas. The technical system has the function of connecting these different places, thus imposing conditioning by the infrastructure, which allows the message or work to be registered, transmitted, circulated, maintained. The technical system that concerns us here is that of the social networks of the Internet through the use of smartphones, which by definition facilitate the connection between Internet users. It is also a transmission-diffusion system in instantaneous mode. Today, the widespread use of smartphones across all segments of the population has led to increased media coverage of events.

It must be said that this technology, which has never ceased to amaze us, still abounds in enormous inexhaustible potential; it has already completely disrupted photography practices, exacerbating our consumption of images. The prodigious increase in the production and dissemination of images of all kinds, in the media as well as in our perceptual environment, is undoubtedly a fundamental characteristic of our century, we are truly settled in the civilisation of the image; an image culture is gradually being implemented in the minds of our fellow citizens. This inflation, as we know, has progressed with the development of social networks, and the adoption by the general public of new digital shooting solutions. The freedom to photograph without limits is one of the main consequences of acquiring mobile phones with an integrated camera and internet connection. In this study, the modalities of immediacy and ubiquity will make it possible to share visual messages everywhere. The power of social networks in terms of audience gives them an extraordinary impact more than any other media. The Internet and digital imaging will therefore lead to the emergence of a new photographic function that Hémon describes it as “conversationaP". He adds that "while photographic functions have always been made for dialogue, 
they have now become an element of language, where each image is a semantic element that everyone can understand' (2010, p. 2) [7]. A regime of hyperconsumption of images to be consumed in the moment is taking hold in our perceptive habits; amateurs are seduced by this freedom, and are entering a regime of photographic profusion that has continued to develop. At the same time, new rituals of exchange are set up around the screens, the camera quickly becomes " $a$ tool for sharing oneself and one's intimacy" as Mahé states (2014, p. 98) [8]. For Hugon, "the device is no longer just a leisure tool, it is a relational function, like a dimension of a sociability operator, perhaps a real extension of the person" (2006, p. 6) [9]. The freedom and autonomy acquired thanks to smartphone photographs are reflected in the commonplace sharing of images via the Internet.

The productions, which are the subject of our analysis, are therefore carried out by amateurs, who are at the heart of the system. If amateurs are important contributors to the Internet users who follow them, on the other hand, content production is severely disowned by professionals, because these experiences obviously raise many ethical questions.

\section{Discursive Marks of Emotion}

Faced with many audiovisual stimuli, we experience all kinds of feelings or emotions: pleasure, attraction, repulsion, anxiety, hatred, sympathy, admiration, joy, fear, anger, etc. It has long been known that some television programmes or films can sometimes have sufficient emotional value to bring about changes in attitude. Anxious film content, violence programmes, erotic images, comic images, the display or treatment of dramatic events, such as natural or provoked disasters, accidents, wars, crimes and many others, very often sought and appreciated by many audiences, trigger emotional reactions. Communicators have understood this well and use emotion to improve the effectiveness of functional communication messages. Indeed, emotion is likely to attract the attention of the receiver given his emotional load, and is therefore a calling value and a catchphrase. It therefore seems that emotion is one of the essential driving forces of the media. In general, in such situations, media discourses tend to converge in the registers of dramatization, compassion, feeling, anger, denunciation to the detriment of the register of rationality. This type of iconic writing is justified according to Zuili (2019) [10], "in a world where emotion is thrown in front of the stage, there is an emotional contagion that social networks promote".

To go further in exploring emotion as a practice that can raise awareness among crowds and as an element that encourages action for a cause, we must seek to deepen the way it works.

Psychology has always been interested in the notion of emotion; it proposes a variability of definitions of this term. Jamet defines it as "the reaction to a destabilizing situation" (2004, p. 80) [11]. According to Lamizet, emotion can refer to "the set of impulses and dynamics that structure the reality of the subjective ex- 
perience" (2004, p. 35) [12]. Indeed, emotion belongs to the very nature of subjectivity, very often you let your heart speak, as a general rule, facts take second place and emotion comes first. The first characteristic of emotion in the media, especially iconic media, according to Lamizet is that: "the representation of emotion is part of an aesthetic of the subject in his singularity" (op.cit. p. 35) [12]. The singular dimensions of these events are marked by the designations of the young woman and the little boy, their names, their first names, their ages, which make them people. Singular persons named: Monique Koumatekel or Blériot Tsanou, whom the reader can identify with the image. They are proven and produce the emotion that these cases provoke. To try to understand what this emotion conveyed by social networks consists of, only one time of the event is retained: the surgical intervention using a blade on a pregnant woman of twins, visibly deceased, and who is about to give birth, by her sister in the hospital compound. If the emotion arises, it is more about presenting a moving situation in itself, recognized as such by the reader. We can analyze the iconic discourse of these videos and identify the elements that contribute, each in a specific way, to the staging of the emotion. The first element is, of course, the central element: the adherence to the speech, the credibility of the video broadcast. However, emotion is perceived as such only because of the sincerity that is granted to the person who lives it or claims to share it: one must be able to believe in the sincerity of the enunciator. This sincerity is confirmed by the fact that, on the same day, the other media took up the subject, amplifying it but adopting a different discursive approach. Images broadcast on social networks would never have had their place in the TV newspaper, for example, because death cannot and should not be exposed in this way. The visibility contract that these videos offer us is based on the existence of a reality to be shown, on an objectivity of seeing; reality is within reach. What is shown is not shaped by representation or processing codes. We are in the register of truth, the reader who attends this event, within the framework of social networks, and not within the framework of a fiction, integrates that it is reality. The video is kept as a whole to produce the effect, while at the same time allowing a precise and objective representation. The enunciator captured the visual information on the spot, he was present at the very moment the event occurred. Internet users, readers of these videos do not wonder about the status of what they see: these images have the particularity of having exposed in their most raw and direct reality, the tragic fate of the dead people. In this case, death became public, from the moment it occurred in front of image sensors and in the context of a planetary event. For example, in the case of Monique Koumatekel, the emotion here comes from the fact that we are sensitive to the reality of the subject: death is obviously there, the horror of the scene, both by the blood and by the madness of the caesarean section performed in the open air. Monique Koumatekel's inert body serves as the symbolic centre of the image: it condenses the reader's attention on it, precisely because of its mediation dimension. We contemplate images whose sight is painful 
to us. The choice of a tight framing, from a frontal and horizontal point of view by the cameraman, marks the background of the illustration, the hospital courtyard, as if it were a window open to our own eyes; the emotion coming from a recognition and appropriation of the subject by the reader. Hence, the quasi-silence of the commentary to explain or describe the scene, is intended to be more eloquent than a long speech. Death is obviously there, and the silence of the commentary is very disturbing. Only the sound atmosphere is perceptible; we hear the comments of the public present on the site, and especially the members of the family who shout out their pain. This way of playing with emotion lies in this suggestion of the unspeakable nature of the event. Everything is too violent, oversized. While the reader might expect a detailed account, he notes this paradoxical absence. This type of event that appears on telephone screens creates a major contradiction for the viewer: on the one hand, he is fascinated by the images that reflect his own emotions and, on the other hand, he is a rational being who seeks to understand what he sees. For Charaudeau, "the misunderstanding comes from the fact that we are asking for images and at the same time, explanations. And the two are contradictory. the images are addressed to emotion, and the explanations to reason" (2001, p. 14) [13]. This contradiction highlighted here by Patrick Charaudeau explains the choice made by the enunciator whose aim is essentially the production of emotion.

The second element of the video is the group of people present at the scene and around the scene; some describe what they see, and thus provide information to the reader about what he sees, while others shout their pain. The people present are, in fact, in the same position as the reader, since we see them from behind. The reader could identify with them, because he is, like them, in a spectator situation. It is therefore singular individuals who are shown to the reader and who make him/her establish a singular relationship with the event and its actors. This staging creates a split between two emotions: the one to be seen, which is experienced at the same time by the crowd, and the one we can experience as a reader of this video. The emotion is also physically manifested by the mother of the deceased in tears, helpless and inconsolable, who sees the story played out before her eyes.

Faced with the peak of the event of the extraction of the two babies from their mother's womb, which also offers the reader the possibility of crying with the families, there is a strong perception of emotions experienced and the sharing of this emotion.

It is only a question of emotion; that of the family, the crowd, and beyond, of an entire society. All these direct or indirect actors of the event are described by bodily states that strongly manifest the emotions experienced. What emotion is this about? If Man suffers at this event, it is to see lives destroyed that could have been saved; it is to see the distancing of medical personnel from death and suffering; negligence, indifference, contempt of hospital personnel, all these elements are enough to underline its atrocious character. The emotional shock is 
also caused by a series of oppositions: the open-air operating theatre is in opposition to the hospital's conventional operating theatre; the cousin acts in place of the doctor, all this within the hospital's walls.

In the case of Tsanou Blériot, the emotion also comes from the fact that we are sensitive to the reality of the subject: it comes from the maximum distance established between the nurses, the young person himself, and the social belonging that he symbolically and institutionally represents: it is a young student of the Deido High school who was stabbed by one of his classmates. There remains this feeling of strangeness of a document that gives itself for photography, and at the same time offers clues that it is something unreal, for ethical, moral reasons affecting the very nature of what can neither be told nor shown.

In these case studies, we were able to notice on the one hand, that the videos do not reveal real discursive strategies. There is certainly no real staging in the visual treatment of what is in itself, moving events: it is the triumph of a certain type of visual emotion, we are dealing with a particular emotion, the one that requires a reaction. The facts speak for themselves, and that confrontation with this reality generates trauma. On the other hand, when the spectacle of suffering and trauma was accepted, because it was considered part of the news, then an emotional word could be used to express solidarity. The call to sensitivity, to immediate reaction, without mediation of these videos, calls for action through emotion.

\section{From Emotion to Mobilization}

To make this analysis of the figure of mobilization, we relied on all the means that reported public reactions to these videos or their treatment by the media. Indeed, the material of these analyses obviously reflects a good part of the Cameroonian opinion. In general, the images of these two videos shocked a lot because they have this particularity that they exposed in their most raw reality the tragic fate of Monique and Blériot. In both cases, death became public, from the moment it occurred in front of image sensors, one could even say that it became a spectacle.

In fact, these videos have specific characteristics that are related to the nature of the object being filmed. This choice of the filmed object is not neutral, but an existing societal issue of which the reader is an integral part. The producers of these videos strive to produce images in which the public can identify with themselves, which encourages them to adopt a receptive attitude towards the subject. The visual message is therefore designed in such a way as to encourage the reader to invest. As a result, it is often based on major societal problems. The producer captures and seizes images whose components affect the emotional sensitivity of the audience. If the latter sometimes has the impression that these images are addressed to him personally, and not to a general anonymous audience, it is because these images contain sensory elements that evoke very personal evocations and connotations. Thus, the strength of these images, which go 
beyond the simple emotion linked to traumatic events, also lies in the marking made by the producer whose rhetoric or staging is that of denunciation, especially in the video on Monique Koumatekel.

From the reactions related to these videos, we have isolated several postures of Cameroonians. At a first level, these are in what we will call the posture of fear: many have had reactions of compassion, immediate emotion, sadness, distress, excitement and indignation; for example, among the many titles that have dealt with this subject and that have gathered the reactions of several Cameroonians, let us mention the article published by Mohamadou Houmfa: "The Monique Koumatekel case: a marker for Cameroon's social history" on 29 March 2016: "I was shocked by the apocalyptic scene we saw", said one interviewee about the Monique Koumatekel video. "I am shocked by these images. There are no words to describe the horror (...). Like millions of Cameroonians, I saw terrifying and nightmarish images", says one interviewee. Another recounts: "I was very touched by this story, especially since this kind of tragedy happens very frequently in Cameroon, because of the amount to be paid to be treated quickly in hospitals. You have to pay a deposit before you see a doctor or have surgery". In addition, the tweet of Cameroon's Minister of Public Health, Mr. Manaouda Malachie, had toured social networks on Saturday, March 30 after the murder of the young High School student Blériot. He said: "While strongly disapproving of the behaviour of some staff at Deido District Hospital, I would like to express my closeness to the family of the victim of this heinous act. I have just ordered an investigation to determine, as a matter of priority, who is responsible for this case".

Some reactions expressed in the information media suggest a certain form of elaboration of a reasoning on the part of Cameroonians, a posture of denunciation, rejection. First, Cameroonians seem to accept these images and consider them as part of the public debate. Indeed, they criticize the inconsistencies and dysfunctions of the health system in Cameroon, which are reflected in the videos. It should be noted here that the Medical Institution and its staff are subject to many criticisms. It is very often said that many patients brought by their families in medical and/or surgical emergencies are neglected and do not receive any care until payment is made. We pay to have a medical certificate even without seeing a doctor. We pay for better care. We pay to get the attention of the nurses. We pay for our safety, to prevent a newborn baby from being stolen or a loved one's organs from being stolen from the mortuary. Therefore, the contemplation of these images of deceased persons, where the responsibility of the Medical Institution and its staff is called into question, generates for many a feeling of anxiety; this posture can be understood by the fact that the fate of the two victims could have been the fate reserved for each of us. We see here that there is a refusal of what could degrade the viewer, a refusal of what Boltanski calls "corruption" (1993, p. 13) [14] through these images and the suffering of others displayed in them. The degree of importance of these images is so strong, they are 
not cartoons or video games, they are reality. Boltanski stresses that it is when "the suffering object is given for real, as is the case, for example, in certain television reports, that its contemplation is problematic" (op. cit., p. 42) [13]. Faced with these images, Internet users who recognize suffering and accept it as such by providing a discourse marked by emotion, ultimately develop a public word; and we note here that this approach, which encourages people to act by participating in public action, is similar to this public word that gives meaning to mobilization. Examples of this can be found in both cases, which are the subject of our study: the day after the scene at Laquintinie Hospital, hundreds of demonstrators gathered outside the hospital with banners bearing the following messages: "No more Monique Koumatel in my country" or "Because of this system, the poor have no access to health care", but also, "We want justice", or "Let justice be done". Other demonstrations took place, such as the one that brought together nearly 200 people, during which the demonstrators demanded the resignation of the hospital Director and the release of the victim's sister, the one who performed a cesarean section on the ground with a blade, arrested by the police. It is also worth noting the numerous reactions of the Government of the Republic of Cameroon which, in order to condemn the misinformation on social networks, initiated a communication to present a version of the facts that seemed to contradict the one given by the family: Monique Koumatekel reportedly died four hours before arriving at the hospital, causing a further wave of public outrage. As for the young Blériot, who was stabbed to death by one of his classmates during the handing over of second Term report cards, it was the nurses' behaviour that caused outrage. Indeed, how can we understand the deliberate disregard of any oath of medical secrecy? How can we understand that images of an operating room, an emergency room, a family pain, a tragedy in a hospital are put on the Internet by the medical staff themselves. It is still intolerable that we lose respect for the dead. A behaviour therefore provoked anger among Internet users, who shouted alert. It should be noted here that the Minister of Health's sanctions were swift, as they helped to ease tensions. Nevertheless, the funeral of young Blériot attracted a large crowd and was exceptionally well attended.

Indeed, such public reactions can be understood today. From this perspective, with Moscovici (1672) [15] and Castellan (1970) [16], in the field of social psychology, studies on the mechanisms of attitude change prove that to bring about such changes, propaganda techniques can focus on cognitive, emotional and conative elements. Emotional shock, more specifically, can lead to changes in attitude, and some people are particularly sensitive to it. It is here that the clash of images makes it possible to raise awareness among crowds and encourage action in favour of a cause. It is easier to achieve action when examples are provided. Social networks are nowadays particularly effective in this respect since they present "live" videos.

There is therefore, on the part of Internet users, an intentionality, an explicit 
willingness to say what we think and what we believe. The many Internet messages emanating from them or their participation in any form of public action is an entry into the public space, a way of making their words known in the hope of involving as many people as possible in order to stimulate a debate to change things. This word is already in a way a kind of principle, a public word and refers to the address to an unlimited number of people, including the authorities: " $s o$ we are all Koumatekels". It is by giving voice that they try to put the authorities on notice to act in a situation where direct action is difficult or impossible.

\section{Conclusions}

To conclude, this paper shows that, in the type of discourse conveyed by social networks about society, through information and communication technologies, emotion is one of the essential springs. This emotional construction of the social reality always creates a link between feeling and action; the feeling of revolt, but also the feeling of denunciation or call for sanction, pushes to act through a collective act of revenge. It should also be noted that this type of discourse carried by social networks relaunches reflection on the relationship between information and communication technologies and political forms. Among the new features offered, the most promising, which marks a break with the media process and its unilaterality, is the possibility given to everyone to be a producer-diffuser of information. We are witnessing new sociabilities and the creation of new public spaces that can influence the decision-making process and find a strictly political outlet. This type of discourse is therefore likely to affect public authorities, and would it mark the end of political stagnation?

The reading and analysis of the two videos, which are the subject of our study, show that the style of this type of production is quite easily recognizable. First, it is mainly characterized by the highlighting of statements that produce emotion because of images of catastrophic situations. They are like the substratum of an unbearable and almost unspeakable situation: death is often there. The information provided is measured more in terms of emotion than in terms of semantic meaning. The factors of surprise, unusual, bizarre, and strange, constitute at least part of the call value and cause an effect of cognitive dissonance, i.e. an effect of contrast or opposition to what is expected by the receiver.

In fact, these video productions broadcast on social networks by the public have specific characteristics that are part of its vocation. Designers strive to produce images that are affectively and emotionally charged and that generate awareness, compassion, outrage and mobilization. Perhaps we can see in this approach, a megaphone, a quick and effective way to make ourselves heard, a desire to launch the debate, to attract attention, to move things forward and to identify the people responsible and the dysfunctions so that this does not happen again.

\section{Conflicts of Interest}

The author declares no conflicts of interest regarding the publication of this paper. 


\section{References}

[1] Noah, D.-A. (2016) The Koumatekel Affair: A Cameroonian Tragedy: The Challenge of Journalistic Information in the Age of Social Media. ESSTIC, University of Yaoundé II, Yaoundé.

[2] Charaudeau, P. (2000) A Discursive Issue of Emotion: About the Effects of Pathemization on Television. In: Plantin, C., Doury, M. and Traverso, V., Eds., Emotions in Interactions, PUL, Lyon, 125-155.

[3] Debord, G. (1967) The Society of the Show. Buchet-Chastel, Paris.

[4] Ehrenberg, A. and Chambat, P. (1993) Reality Shows, the New Age of Television? Esprit.

[5] Volton, D. (1992) The Contradiction of the Mediatized Public Space. Hermès, No. 10, The French National Center for Scientific Research (CNRS), Paris.

[6] Nel, N. (2005) Television Systems. In: Bourdon, J. and Jost, F., Eds., Thinking Television, Armand Colin, Paris, 59-73.

[7] Hémon, J. (2010) Social Networks and the Photography Market. Cahier Louis-Lumière, No. 74.

[8] Mahé, A. (2007) The Relational Poetics of the Photographic Act. Sociétés, No. 98, 95-100. https://doi.org/10.3917/soc.098.0095

[9] Hugon, S. (2014) Introduction: A Sociality without the Social. Sociétés, No. 124, 5-6. https://doi.org/10.3917/soc.124.0005

[10] Zuili, R. (2019) How Social Networks Have Fostered Emotion at the Expense of Reality. Huffpost Contributor. https://www.huffingtonpost.fr

[11] Jamet, C. (2004) The fading strategy: about the december 1999 storms. Mots, No. 75, ENS, Editions.

[12] Lamizet, B. (2004) The Aesthetics of the Limit and the Dialectic of Emotion. Mots, ENS Editions.

[13] Charaudeau, P. (2001) Television and War: Distortion or Construction of Reality? INA De Boeck University, Bruxelles.

[14] Boltanski, L. (1993) Suffering at a Distance: Humanitarian Morality, Media and Politics. Métailié, Paris.

[15] Moscovici, S. (1972) Introduction to Social Psychology. Armand Colin, Paris.

[16] Castellan, Y. (1970) Introduction to Social Psychology. Armand Colin, Paris. 